\title{
Verifique sus conocimientos sobre
}

\author{
Jordi Galimany
}

Enfermero. Profesor Asociado de la Escuela Universitaria de Enfermería de la Universidad de Barcelona.

Supervisor del servicio de diagnósticos en la clínica Teknon. Barcelona. España

LA PROTECCIÓN RADIOLÓGICA en radiodiagnóstico merece una atención específica que abordaremos en esta entrega que forma parte de una serie sobre pruebas complementarias que se inició en el Nursing2007 de abril.

La utilización de técnicas basadas en el uso de radiación ionizante es muy habitual en nuestro entorno laboral. En estas técnicas intervienen cada vez más profesionales de enfermería, tanto desde un punto de vista de la realización, como de supervisión y de apoyo del médico en su realización.

Nuestro objetivo es familiarizar a los/as profesionales de enfermería con la protección radiológica y con el conocimiento de las herramientas y mecanismos de que disponemos, o deberíamos disponer, en nuestros centros asistenciales para aplicarlos desde el punto de vista de protección de la salud.

Es importante aclarar que hay disciplinas médicas, diagnósticas o terapéuticas, que utilizan otras radiaciones ionizantes (alfa, beta y gamma), diferentes a las radiaciones X empleadas en radiodiagnóstico. En tal caso, aunque la base sea común, pueden estar sujetas a otras medidas de prevención.

Finalmente creemos que de esta manera combatiremos posibles temores y prejuicios en torno a los rayos X; tendremos claras las principales precauciones que podemos tomar y cómo las gestionamos en el desempeño de nuestras funciones diarias como enfermeros/as desde un punto de vista de riesgo laboral.

1. La radiación $X(R X)$ que se utiliza en la realización de radiografías:

a. Es inocua.

b. Es una fuente de energía que no supone ningún riesgo para el paciente.

c. Es una fuente de energía que no supone ningún riesgo para el personal sanitario.

d. Puede tener efectos adversos.

2. ¿Qué efectos biológicos puede provocar la RX en la materia viva?

a. Efectos somáticos y efectos genéticos.

b. Efectos a corto o a largo plazo.

c. Puede hablarse de efectos probabilísticos o deterministas.

d. Todas las respuestas son ciertas.

3. ¿Qué tejidos son más sensibles a los efectos de la RX?

a. No hay distinción, todos los tejidos se afectan de la misma manera. b. Los efectos dependen de la edad de la persona.

c. Los tejidos con mayor renovación celular son los que se pueden ver más afectados.

d. Todas las respuestas son falsas.

4. ¿Qué mecanismos de protección hay ante la $\mathbf{R X}$ ?

a. No hay mecanismos de protección, puesto que estas radiaciones son inocuas.

b. Depende de si se trata de una exposición puntual o de exposiciones habituales.

c. Sólo deben tomar medidas los profesionales que realizan radiografías.

d. Existen diferentes mecanismos de protección que se refieren a la distancia, al blindaje y a mecanismos de control y medición de la radiación.
5. ¿Qué sucede con la realización de radiografías fuera de las áreas específicas de irradiación, como habitaciones, unidades de cuidados intensivos, quirófanos, consultas de traumatología, boxes de urgencias, etc.?

a. En estas zonas no se pueden realizar radiografías.

b. Deben tomarse el máximo de medidas de radioprotección.

c. Sólo se toman medidas en caso de realizar fluoroscopia.

d. No hay que tomar ninguna medida, puesto que se realizan RX de forma esporádica.

6. Las imágenes de la figura:

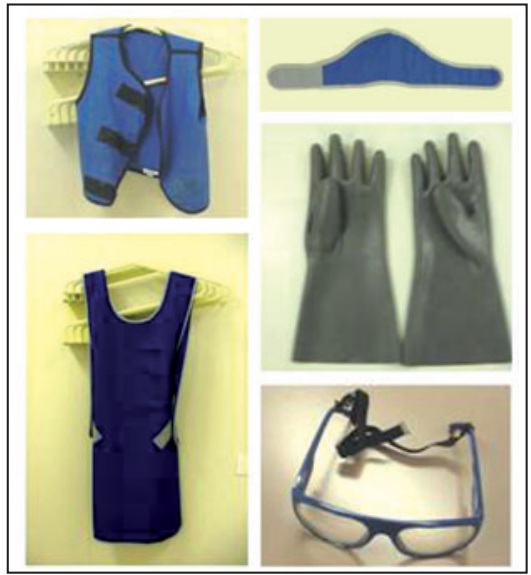

a. Son elementos de protección plomada.

b. Sólo hay que utilizarlos en las pruebas con exposiciones muy prolongadas a la radiación.

c. Es opcional disponer de ellas en las salas de RX.

d. Todas las respuestas son ciertas. 


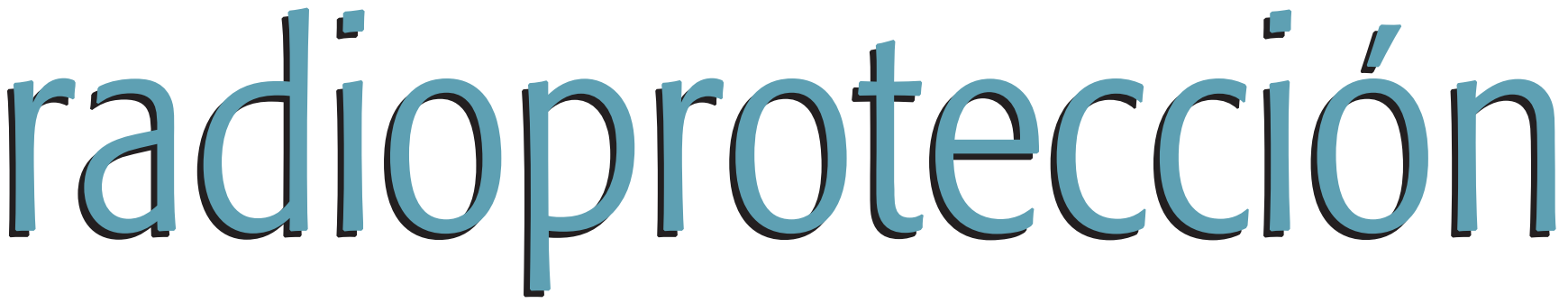

7. En lo que se refiere a la medición de la radiación:

a. La RX no se puede medir, es muy baja.

b. Se dispone de dosímetros personales y de área para medir la radiación.

c. Las mediciones se registran mensualmente.

d. Las respuestas b y c son ciertas.

8. Las imágenes de la figura:

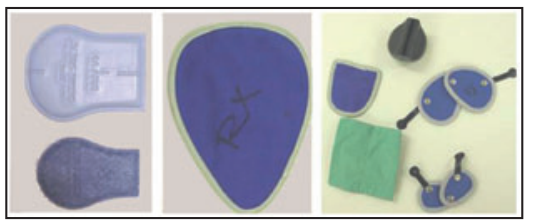

a. Son elementos de protección plomada

b. Se utilizan para proteger las gónadas de los/las pacientes.

c. Es obligatorio disponer de estos elementos y utilizarlos sin excepción.

d. Todas las respuestas son ciertas.

9. ¿Qué medidas hay que tomar ante la presencia de un acompañante en una exploración con RX?

a. Los familiares y acompañantes no pueden estar en las salas de RX.

b. Hay que explicarles los riesgos derivados de permanecer en la sala de RX.

c. No hace falta protegerlos con protección plomada, pues han querido permanecer en la sala.

d. Las respuestas b y c son correctas.

10.Una gestante, ¿puede realizarse una $\mathbf{R X}$ ?

a. No, en ningún caso.

b. Depende de la zona anatómica de la radiografía.

c. Depende del tiempo de gestación.

d. Sí.
11. ¿Se puede hacer una radiografía una mujer que está dando el pecho?

a. No, en ningún caso.

b. Sí, pero luego deberá suspender la lactancia durante un tiempo.

c. No si la radiografía es de una zona próxima a los pechos.

d. Sí.

12. ¿Qué medidas hay que tomar ante la exposición de una gestante a los RX?

a. Se medirá la dosis recibida por el útero y se tomarán medidas en función de esta dosis en cada caso concreto.

b. Sólo hay que tomar medidas en las tomografías computarizadas.

c. No hay que tomar medidas si la dosis es baja.

d. No hay que tomar medidas en ningún caso.

13. Magnitudes y unidades de medida de los RX:

a. Los sieverts y los milisieverts son las unidades de medida de los RX.

b. La radiación no se puede medir.

c. Sólo se miden radiaciones alfa y beta.

d. Todas las respuestas son falsas.

14.Para garantizar el control, la seguridad y la calidad en los procesos y procedimientos diagnósticos llevados a cabo mediante $\mathbf{R X}$ :

a. Hay una legislación específica que los controla y regula.

b. Los equipos y salas de RX se someten a controles anuales para garantizar su correcto funcionamiento.

c. Las administraciones sanitarias, en el marco de la Unión Europea, implementan programas de garantía de calidad en las instalaciones de radiodiagnóstico.

d. Todas las respuestas son verdaderas.

15.Los enfermeros/as, en nuestra práctica diaria, podemos tener contacto con procedimientos relacionados con la emisión de RX.

a. Disponemos de herramientas que nos permiten gestionar estas situaciones y debemos conocerlas.

b. Debemos evitar, de todas maneras, el contacto con los RX.

c. Las medidas de protección afectan y han de tomarse también respecto al público en general (pacientes o acompañantes).

d. Las respuestas a y c son correctas.

\section{Respuestas}

1. d. Inicialmente, cuando Wilhem Conrad Röntgen descubrió la radiación X en 1895, no se conocían sus efectos biológicos. El descubrimiento permitía, por vez primera, estudiar estructuras del cuerpo de manera hasta el momento insospechada, si no era post mortem en una necropsia. Sin embargo, pese a los beneficios indiscutibles, también existen efectos indeseables de los RX. Su mecanismo de producción genera una energía que, al interaccionar con la materia viva y ser absorbida por las células de los tejidos, puede provocar alteraciones de diversa índole. Debe considerarse que en cualquier exposición a los RX existe un riesgo para las personas que se encuentran en su zona de influencia, sean profesionales sanitarios, pacientes o acompañantes. Recordemos que los RX no 
sólo se utilizan en las radiografías, sino que también se emplean en la obtención de la imagen por tomografía computarizada (TC) y en la mamografía. La posibilidad de efectos adversos y las consideraciones y medidas que mencionamos son extensibles también a dichas disciplinas diagnósticas.

2. d. Los efectos biológicos de las radiaciones ionizantes pueden clasificarse en:

- Somáticos, que aparecen a partir de una dosis umbral (la mínima dosis de radiación capaz de producir un efecto perceptible) por debajo de la cual no se producen; su gravedad depende de la dosis de radiación recibida.

- Genéticos, que no aparecen en la persona irradiada, sino en su descendencia.

- Según el tiempo de aparición de los efectos, se habla de efectos a corto plazo (menos de 6 meses) o a largo plazo (aparición de los efectos después de meses o años de la irradiación).

- Según la dosis recibida por el tejido vivo, los efectos biológicos también pueden clasificarse en:

- Probabilísticos o estocásticos (aleatorios e independientes de la dosis umbral).

- Deterministas o no estocásticos (dependen de la dosis umbral por debajo de la cual no se producen dichos efectos).

3. c. El grado de radiosensibilidad de los órganos está en función o en relación directa con su actividad celular. De esta manera, los tejidos con más renovación celular son más sensibles a la acción de la radiación (radiosensibles). Por el contrario, los órganos y los tejidos con una renovación celular menor son más resistentes (radiorresistentes). Los linfocitos, las células hematopoyéticas, las células del epitelio intestinal y las células reproductoras femeninas y masculinas son muy radiosensibles. En cambio, las neuronas, las células musculares y las de los tejidos conjuntivo y cartilaginoso son radiorresistentes.

4. d. Los mecanismos o medidas de que disponemos frente a los RX (radioprotección) se pueden agrupar en 3 grandes aparatados: métodos de barrera física, métodos técnicos, y sistemas de medición y control. El principal elemento de barrera física es el plomo; las paredes y los cristales de las salas de RX están recubiertos de este metal.

En los techos y los suelos de las salas el grosor del hormigón hace innecesario el plomo. Como veremos más adelante, también la vestimenta plomada utiliza este material como base. Por otro lado, las técnicas empleadas para la realización de RX, sobre todo la distancia, son otro elemento para reducir la dosis de radiación. En último término disponemos de dosímetros, de mediciones y de toda la legislación referente a las radiaciones ionizantes.

5. b. Fuera de los departamentos y servicios de RX preparados para el uso de radiación es donde los/las profesionales de enfermería están más expuestos a la radiación. En las áreas de traumatología y urgencias las RX se realizan de manera habitual, y los profesionales de enfermería que desempeñan sus funciones en estas áreas han de extremar los comportamientos seguros. En muchos casos no se dispone de la protección plomada para protegernos, y es habitual que el único recurso sea alejarse de la exposición (usamos el método técnico de protección de la distancia), pero esto no es posible cuando hay que permanecer al lado del paciente para garantizar su integridad y seguridad. En este caso hay que vestirse con el vestuario plomado, alejarse todo lo posible de la zona de irradiación y, en el caso de fluoroscopia, intentar minimizar su duración.

6. a. Todos los elementos que aparecen en la imagen son protecciones plomadas. Son mecanismos de protección de barrera física y están hechos de plomo, que -como ya sabemos- es un metal que no deja pasar los RX. Los delantales, los protectores tiroideos, las gafas y los guantes plomados son elementos básicos para la protección en los procedimientos que requieren nuestra presencia cerca del foco de emisión: procedimientos de reducción de fracturas, sujeción y movilización; en pacientes críticos para garantizar su seguridad; apoyo a los técnicos en situaciones más complejas, etc. Existen diferentes diseños, y se dispone incluso de guantes para uso quirúrgico. Está estipulado por ley que este material debe estar disponible en las zonas donde se utilizan RX.
7. d. La medición de dosis de RX mediante dosímetros es una herramienta de radioprotección básica. Mediante los dispositivos de diferentes formas y modelos, podemos saber la dosis que ha recibido la persona que los porta. Esta medición o control se realiza mensualmente. La dosis de radiación de cada persona es acumulativa y queda registrada. Los/las profesionales que han de llevar dosímetro son los que intervienen habitualmente en el uso de RX. Pueden ser técnicos/as, enfermeros/as, personal auxiliar sanitario o médicos.

Hay dosímetros especiales de muñeca para profesionales que están en quirófanos, salas de hemodinámica, mamografía o radiología contrastada donde se realizan técnicas con fluoroscopia que, en principio, implican más dosis. También hay dosímetros especiales para las profesionales embarazadas que requieren un control específico.

8. d. Las imágenes corresponden a protectores gonadales plomados. Los protectores gonadales deben utilizarse sistemáticamente para proteger las gónadas de los/las pacientes, que -como hemos visto anteriormente- son una de las zonas más radiosensibles. También hay dispositivos plomados para proteger las glándulas mamarias. Estos dispositivos tienen una traducción radiográfica de color blanco muy intenso que ya conocemos; ello se debe a que el plomo absorbe mucha radiación, y precisamente por eso nos interesa situarlo encima de zonas que no queremos irradiar. Por otra parte, es cierto que la normativa obliga que los departamentos de RX dispongan de estos elementos de radioprotección.

9. b. Los acompañantes o familiares que, por algún motivo, deban o quieran permanecer en las salas de RX durante las exploraciones han de tener cumplida información de los riesgos que comporta la exposición a los RX. No podemos negarnos a su presencia en el momento de la realización de la $\mathrm{RX}$, a no ser que la práctica sanitaria y el sentido común lo desaconsejen. Las personas que permanezcan en la sala deberán protegerse con elementos plomados adecuados. Los casos más habituales son los de acompañamiento de niños, en que 
el impacto de la exploración se minimiza mucho al estar con el familiar.

10. d. Una mujer embarazada puede hacerse una RX, aunque debe evitarse en la medida de lo posible. Durante el primer trimestre del embarazo el riesgo de alteraciones por efecto de la radiación es más elevado, puesto que en esta fase embrionaria es cuando hay división celular. En la fase de crecimiento posterior del feto el riesgo, aunque existe, no es tan elevado como en el primer trimestre.

Por otro lado, no depende de la zona anatómica que se va a estudiar, aunque las medidas de radioprotección sobre el vientre de la madre pueden variar en función de ésta. Cada caso se valora en función del riesgo/beneficio de la obtención de la RX. Si finalmente se decide realizar la exploración, hay que garantizar que el feto reciba la mínima dosis posible.

11. d. Las mujeres que dan el pecho pueden realizarse una RX. Esto incluye, también, RX próximas a los pechos. No es necesario suspender la lactancia posteriormente a la realización de la RX. En todo caso, se aplican los criterios habituales de radioprotección e indicación de la exploración.

Habría que suspender momentáneamente la lactancia cuando se administra contraste intravenoso; en tal caso la madre debe abstenerse de dar el pecho durante $36 \mathrm{~h}$, ya que una pequeña parte de este contraste pasa a la leche materna.

Las glándulas mamarias son una zona anatómica radiosensible. Es por ello que se pueden proteger con los protectores plomados diseñados a tal efecto. También hay que tener presente que esta protección es aplicable cuando la glándula está en fase de formación en las niñas.

12. a. Ante una paciente en edad de procrear, hay que preguntar sistemáticamente por la posibilidad de embarazo. En muchos casos los/las profesionales de enfermería seremos los primeros en explicarle que va a someterse a alguna técnica con RX. En caso de duda hay que valorar la posibilidad de realizar un test de embarazo o, simplemente, de posponer la RX, siempre que esto sea posible.
Esto evita un porcentaje muy elevado de exposiciones no deseadas a mujeres embarazadas.

Si de todas maneras esta exposición se ha producido, se realiza una determinación de dosis absorbida en el útero; esta determinación es variable en función de diferentes parámetros tanto de la paciente (edad, peso, talla, zona anatómica expuesta, etc.), como del equipo y la técnica utilizada para la realización de la RX, la mamografía o la TC.

13. a. Las unidades de radiación tienen mucho que ver con el tiempo de exposición, motivo por el cual siempre hay que hacer hincapié y mención aparte de las técnicas con fluoroscopia.

Pueden valorarse desde un punto de vista de dosis absorbida, donde de mide la dosis emitida -la unidad internacional es el gray (Gy)-, pero también se puede tener en cuenta desde el punto de vista del efecto biológico que la radiación puede provocar; seria el equivalente humano de la dosis absorbida. Esta dosis es la denominada "dosis equivalente", y la unidad del sistema internacional es el sievert ( $\mathrm{Sv}$ o mSv). Los límites de dosis anuales son distintos para los profesionales expuestos. También hay distinciones de límites en mujeres en edad de procrear, embarazadas, personal de prácticas, menores de 18 años, etc. Otra de las distinciones del límite de dosis puede ser por zona anatómica, dada la diferente radiosensibilidad de las distintas estructuras.

14. d. Todo el proceso de obtención de una imagen diagnóstica mediante RX, desde el momento de la solicitud de la exploración hasta la entrega con su correspondiente informe, está regulada por diferentes normas y leyes. Su objetivo, así como el de los controles anuales a los equipos de obtención de imagen RX, es la vigilancia de la salud de los/las profesionales que intervienen en el uso de RX para asegurar la seguridad de los pacientes y la salud de los/las trabajadores.

15. d. El uso de RX es un elemento de nuestra cotidianidad laboral que podemos gestionar y que no debe provocarnos inseguridad. Al contrario, conociendo los mecanismos de protección transmitiremos a los pacientes la seguridad necesaria en el momento que se plantean dudas sobre qué se les va a hacer y cómo, además de las consecuencias que pudiera generarles el uso o el someterse a técnicas de RX. Las medidas de radioprotección deben ser especialmente observadas en gestantes y en niños. Como decíamos al principio, los RX son una herramienta diagnóstica indispensable, y como enfermeros/as responsables del paciente debemos conocer las medidas de radioprotección, de tal manera que facilitemos su seguridad durante los procedimientos. También para nosotros, enfermeros/as, desde un punto de vista de seguridad laboral en los centros asistenciales es básico conocer el uso y la gestión de los procesos en los que intervienen los RX. ae

\section{Bibliografía}

Asesoría y Control en Protección Radiológica (ACPRO). Manual de protección radiológica en el ámbito del radiodiagnóstico. ICRP-84

Benavies FG, Ruiz-Frutos C. Salud laboral. 3. ${ }^{a} \mathrm{ed}$ Barcelona: Masson; 2006

BOE núm. 178, de 26 de julio de 2001. Reglamento sobre Protección Sanitaria Contra Radiaciones Ionizantes.

Casanova R, Pedrosa CS. Diagnóstico por la imagen 2. ${ }^{a}$ ed. Madrid: Interamericana; 1996.

Comisión Europea. Dirección Europea del Medio Ambiente. Guía para la correcta solicitud de pruebas de diagnóstico por la imagen. Protección Radiológica 118. Luxemburgo: Comisión Europea; 2001

Directiva 1997/43 Euratom del Consejo de la Unión Europea, de 30 de junio de 1997, sobre la Protección de la Salud Frente a los Riesgos Derivados de la Radiaciones Ionizantes en Exposiciones Médicas.

Fucks AW. Principles of radiographic. Exposure and procesing. 2nd ed. Florida, USA: Springfield; 1979.

\section{Webs de interés}

http://www.acpro.es/

http://www.aetr.net/

http://www.csn.es/

http://www.icrp.org/

http://www.sefm.es/

http://www.sepr.es/

Correspondencia: Jordi Galimany Masclans. Departament d'Infermeria de Salut Pública,

Salut Mental i Materno-Infantil.

Campus de Bellvitge.

Pavelló de Govern 3era planta.

Feixa Llarga, s/n.

08907 L'Hospitalet de Llobregat. Barcelona.

Correo electrónico:

jordigalimany@ub.edu 